\title{
Quality of life and toxicity after SBRT for organ-confined prostate cancer, a 7-year study
}

\author{
Alan Jay Katz ${ }^{1}$ * and Josephine Kang ${ }^{1,2}$ \\ 1 Flushing Radiation Oncology Services, Flushing, NY, USA \\ ${ }^{2}$ Department of Medicine, NYU Langone Medical Center, New York, NY, USA
}

\section{Edited by:}

Rachelle Lanciano, Delaware County

Memorial Hospital, USA

Reviewed by:

Seong Ki Mun, Virginia Tech, USA John Austin Vargo, University of

Pittsburgh Cancer Institute, USA

\section{*Correspondence:}

Alan Jay Katz, Flushing Radiation Oncology Services, 40-20 Main

Street, Flushing, NY 11354, USA e-mail:akatzmd@msn.com

\begin{abstract}
Objectives: Stereotactic body radiation therapy (SBRT) yields excellent disease control for low- and intermediate-risk prostate cancer by delivering high doses of radiation in a small number of fractions. Our report presents a 7-year update on treatment toxicity and quality of life (QOL) from 515 patients treated with prostate SBRT.
\end{abstract}

\begin{abstract}
Methods: From 2006 to 2009, 515 patients with clinically localized, low-, intermediate-, and high-risk prostate cancer were treated with SBRT using Cyberknife technology. Treatment consisted of 35-36.25 Gy in 5 fractions. Seventy-two patients received hormone therapy. Toxicity was assessed at each follow-up visit using the expanded prostate cancer index composite $(E P I C)$ questionnaire and the radiation therapy oncology group urinary and rectal toxicity scale.
\end{abstract}

Results: Median follow-up was 72 months. The actuarial 7-year freedom from biochemical failure was 95.8, 89.3, and $68.5 \%$ for low-, intermediate-, and high-risk groups, respectively $(p<0.001)$. No patients experienced acute Grade 3 or 4 acute complications. Fewer than $5 \%$ of patients had any acute Grade 2 urinary or rectal toxicity. Late toxicity was low, with Grade 2 rectal and urinary toxicity of 4 and $9.1 \%$, respectively, and Grade 3 urinary toxicity of $1.7 \%$. Mean EPIC urinary and bowel $\mathrm{QOL}$ declined at 1 month post-treatment, returned to baseline by 2 years and remained stable thereafter. EPIC sexual QOL declined by $23 \%$ at 6-12 months and remained stable afterwards. Of patients potent at baseline evaluation, $67 \%$ remained potent at last follow-up.

Conclusion: This study suggests that SBRT, when administered to doses of 35-36.25 Gy, is efficacious and safe. With long-term follow-up in our large patient cohort, we continue to find low rates of late toxicity and excellent rates of biochemical control.

Keywords: prostate cancer, stereotactic body radiation therapy, quality of life, SBRT

\section{INTRODUCTION}

Several recent studies on stereotactic body radiotherapy (SBRT) for prostate cancer have been published, providing evidence of excellent biochemical disease control with short-term follow-up (1-6). With follow-up of up to 5 years, reported bowel and bladder toxicity has been quite low, and quality of life (QOL) measures have been favorable (7). However, the likelihood of long-term toxicity is not well known, and more studies with longer follow-up are necessary in order to confirm initial reports. As a result, the adoption of prostate SBRT in the clinic has proceeded slowly, though it has recently been accepted by both the American society for radiation oncology (ASTRO) and the national comprehensive cancer network (NCCN). The purpose of our study is to document incidence of bowel, bladder, and sexual toxicity and QOL in a large cohort of patients, with follow-up as long as 8 years. This represents significantly longer follow-up than previously published.

\section{MATERIALS AND METHODS \\ PATIENT SELECTION}

Between 2006 and 2009, 515 consecutive patients with newly diagnosed, non-metastatic, biopsy-proven prostate cancer were treated with SBRT. The first 15 patients were treated on an IRB-approved in-house protocol, and the remainder was treated off protocol, with similar treatment parameters. All patients were consented for treatment and agreed to use of follow-up data for research purposes. Patients were stratified into D'Amico risk groups (lowrisk: PSA $<10$ and Gleason sum of 6 and clinical stage T1c-T2a, intermediate-risk: PSA 10-20 or Gleason sum of 7 or clinical stage T2b, high risk: PSA $>20$ or Gleason sum of $8-10$ or clinical stage $\mathrm{T} 2 \mathrm{c}$ or higher). Seventy-two patients received androgen deprivation therapy (ADT) prior to and during treatment, at the discretion of the urologist.

\section{TREATMENT}

Fiducial-based image-guided SBRT was delivered using the CyberKnife system (Accuray Inc., Sunnyvale, CA, USA), G3 model with multiplan 2.0. The treatment specifics of Cyberknife have been published previously (8). General techniques are outlined here. Four gold fiducials were placed transperineally with ultrasound guidance into the prostate. This was followed by a non-contrast CT scan in the supine position, with alpha cradle immobilization. CT scan was obtained using a 64 slice CT scanner 
with $1.25 \mathrm{~mm}$ slices. Unless contraindicated, patients underwent prostate MRI, and images were fused to CT images in order to better visualize the inferior portion of the prostate. No urinary catheter was used. Dose was prescribed to the planning target volume (PTV), which consisted of a $5 \mathrm{~mm}$ expansion on the prostate, reduced to $3 \mathrm{~mm}$ posteriorly. Homogeneous planning was performed, and dose normalized to the $83-87 \%$ isodose line, with full prescription dose covering at least $95 \%$ of the PTV. Anatomical contours of the prostate, seminal vesicles, rectum, bladder, penile bulb, femoral heads, and testes were generated and dose volume histograms (DVH) constructed. The urethra was not contoured as no constraints were placed on it. Rectal DVH goals were $\mathrm{V} 50<50 \%$ (i.e., the volume receiving $50 \%$ of the prescribed dose was $<50 \%$ ), V80 $<20$, V $90<10$, and V100 $<5 \%$. The bladder DVH goals were V50 $<40$ and V100 $<10 \%$. A typical D50 for the bladder and rectum was $40-45 \%$ of the maximum dose. The femoral head DVH goal was V $40<5 \%$.

During a typical 45 -min treatment, fiducial seeds were tracked and positional adjustments made at 30-60 s intervals. Every morning prior to SBRT, patients underwent bowel prep with Dulcolax ${ }^{\circledR}$ (Boehringer Ingelheim, Germany) and a Fleet ${ }^{\circledR}$ Enema (C.B. Fleet Company, Inc., Lynchburg, VA, USA). In addition, all patients received $1500 \mathrm{mg}$ of amifostine (MedImmune, LLC, Gaithersburg, MD, USA), mixed in saline and instilled into the rectum approximately 15-20 before treatment (9). The radiation dose was 35 $(n=158)$ or $36.25(n=357)$ Gy in 5 fractions, given daily. The first 50 patients treated received $35 \mathrm{~Gy}$. After a report from Stanford documenting the feasibility of using 36.25 Gy (10), we increased the dose accordingly for the next 30 months. Dose was reduced back to 35 Gy due to increased toxicity.

\section{FOLLOW-UP}

The median follow-up for the entire cohort was 72 months. PSAs were obtained at baseline. Post-treatment, PSA was obtained at 3 months post-treatment intervals for the first 2 years, and at 6 months intervals thereafter. The Phoenix definition (nadir +2$)$ was used to define relapse (11).

Urinary, sexual, and bowel QOL expanded prostate cancer index composite (EPIC) scores (12) were obtained from patients at baseline, 3 weeks post-treatment, and subsequently every 36 months for the first 2 years, then 12 months. Acute and late bowel and bladder toxicity was scored according to the criteria set forth by radiation therapy oncology group (RTOG) (13).

\section{STATISTICAL ANALYSES}

Actuarial biochemical control was calculated using the KaplanMeier method and log-rank analysis performed. The likelihood ratio test was used to determine differences in toxicity. Cox multivariate regression analysis was used to analyze the patient factors associated with development of Grade 2-3 late urinary toxicity.

\section{RESULTS \\ PATIENT CHARACTERISTICS}

Patient characteristics are summarized in Table 1. The median follow-up for all patients was 72 months (range, 0-96 months), 26 patients had follow-up for as long as 96 months.

Using D'Amico risk stratification, 324 patients were low-risk, 153 were intermediate-risk, and 38 were high-risk. Median patient
Table 1 | Patient characteristics.

\begin{tabular}{|c|c|c|}
\hline Age at diagnosis & Years & \\
\hline Mean & $68.5(43.8-89.2)$ & \\
\hline Median & $69.0(43.8-89.2)$ & \\
\hline Age at diagnosis & Number of patients & Percent of patients \\
\hline $40-49$ & 4 & 0.7 \\
\hline $50-59$ & 77 & 15.0 \\
\hline $60-69$ & 201 & 39.0 \\
\hline $70-79$ & 196 & 38.1 \\
\hline 80-89 & 37 & 7.2 \\
\hline PSA level at treatment & $\mathrm{ng} / \mathrm{mL}$ & \\
\hline Combined mean (range) & $6.6(1.0-42.9)$ & \\
\hline Median & 5.4 & \\
\hline PSA level at diagnosis & Number of patients & Percent of patients \\
\hline$<4 \mathrm{ng} / \mathrm{mL}$ & 83 & 16.1 \\
\hline $4-10 \mathrm{ng} / \mathrm{mL}$ & 368 & 71.5 \\
\hline$>10-20 \mathrm{ng} / \mathrm{mL}$ & 64 & 12.4 \\
\hline \multicolumn{3}{|l|}{ Risk Category } \\
\hline Low & 324 & 62.9 \\
\hline Intermediate & 153 & 29.7 \\
\hline High & 38 & 7.4 \\
\hline \multicolumn{3}{|l|}{ Clinical Stage } \\
\hline $\mathrm{T} 1 \mathrm{a}$ & 2 & 0.4 \\
\hline $\mathrm{T} 1 \mathrm{c}$ & 462 & 89.7 \\
\hline $\mathrm{T} 2 \mathrm{a}$ & 51 & 9.9 \\
\hline \multicolumn{3}{|l|}{ Gleason Score } \\
\hline 6 & 357 & 69.3 \\
\hline $7(3+4)$ & 84 & 16.3 \\
\hline $7(4+3)$ & 42 & 8.2 \\
\hline $8(4+4)$ & 24 & 4.7 \\
\hline $9(4+5)$ & 6 & 1.1 \\
\hline $9(5+4)$ & 2 & 0.4 \\
\hline \multicolumn{3}{|l|}{ Hormone Treatment } \\
\hline No & 443 & 86.0 \\
\hline Yes & 72 & 14.0 \\
\hline \multicolumn{3}{|l|}{ RT Treatment } \\
\hline $35 \mathrm{~Gy}$ & 158 & 30.7 \\
\hline $36.25 \mathrm{~Gy}$ & 357 & 69.3 \\
\hline
\end{tabular}

age was 69.5 (range, 43.8-89.3 years). The median PSA at diagnosis was $5.4 \mathrm{ng} / \mathrm{mL}$. At last follow-up, 59 patients were deceased, none from prostate cancer. There were 13 deaths in the 35 Gy group and 46 deaths in the 36.25 Gy group, none attributable to prostate cancer. Seventy-two patients received ADT. Of this group, 26 patients were low-risk, 25 were intermediate-risk, and 21 were high-risk.

\section{ACUTE TOXICITY}

All patients were seen at 3 weeks and 3 months post-treatment. At each visit, patients were assessed for bowel and bladder toxicity using RTOG criteria. Overall, 4\% of patients reported Grade 2 urinary or bowel toxicity. Of patients who received $35 \mathrm{~Gy}$, Grade 1 and Grade 2 urinary toxicity was 72 and $4 \%$, respectively, and Grade 1 and Grade 2 rectal toxicity was 76 and 4\%, respectively. There was no Grade 3-4 toxicity observed. 


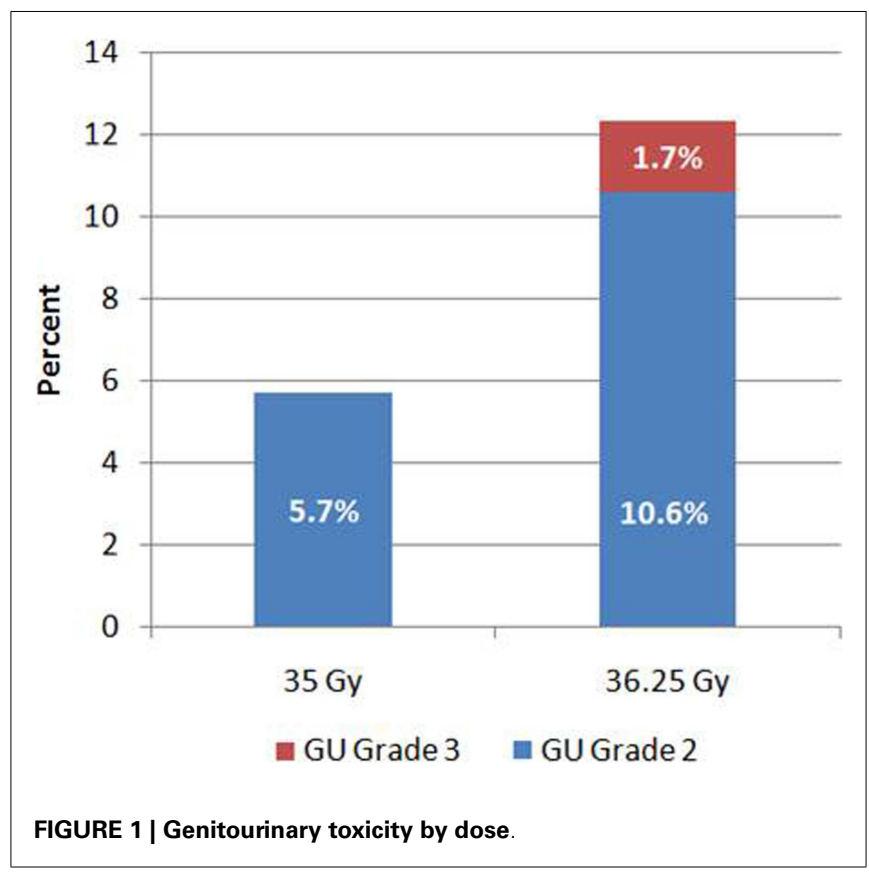

Of patients who received 36.25 Gy, Grade 1 and Grade 2 urinary toxicity was 74 and 4\%, respectively, and Grade 1 and Grade 2 rectal toxicity was 78 and $4 \%$, respectively. There was no significant difference in the incidence of early toxicity for the two doses used.

\section{LATE TOXICITY - SEXUAL POTENCY}

Patients were assessed for sexual potency prior to start of treatment, 375 out of 515 patients reported themselves to be potent. Of this group, $252(67.2 \%)$ remained potent at last follow-up, with $25 \%$ requiring medication. Of the 375 patients initially potent at baseline, 37 received ADT, and only 14 out of 37 (38\%) remained potent at last follow-up. In contrast, 338 patients who were potent at baseline did not receive ADT, and 239 out of $338(70.7 \%)$ remained potent at last follow-up. The difference was statistically significant, $p<0.001$.

\section{LATE TOXICITY - URINARY}

Grade 2 urinary toxicity (mostly severe dysuria, urgency, or obstructed flow) occurred in $47(9.1 \%)$ patients. Of the 158 patients who received $35 \mathrm{~Gy}, 9(5.7 \%)$ had Grade 2 urinary toxicity. In comparison, of the 357 patients who received $36.25 \mathrm{~Gy}, 38$ (10.6\%) developed Grade 2 urinary toxicity (Figure 1). Grade 3 toxicity was significantly higher after 36.25 Gy compared to $35 \mathrm{~Gy}(p=0.005)$, as was the overall incidence of Grade 2 or higher toxicity $(p=0.05)$. Late Grade 3 toxicity occurred in nine patients $(1.7 \%)$ and consisted of either urinary retention requiring surgery or bleeding requiring laser coagulation. All Grade 3 events occurred in patients who received $36.25 \mathrm{~Gy}$.

The median time to development of late urinary toxicity was 18 months (range, 6-60 months). Only 5 of 47 patients (11\%) developed urinary toxicity after 36 months. At last follow-up, 37 of the 47 patients had complete resolution of their symptoms.

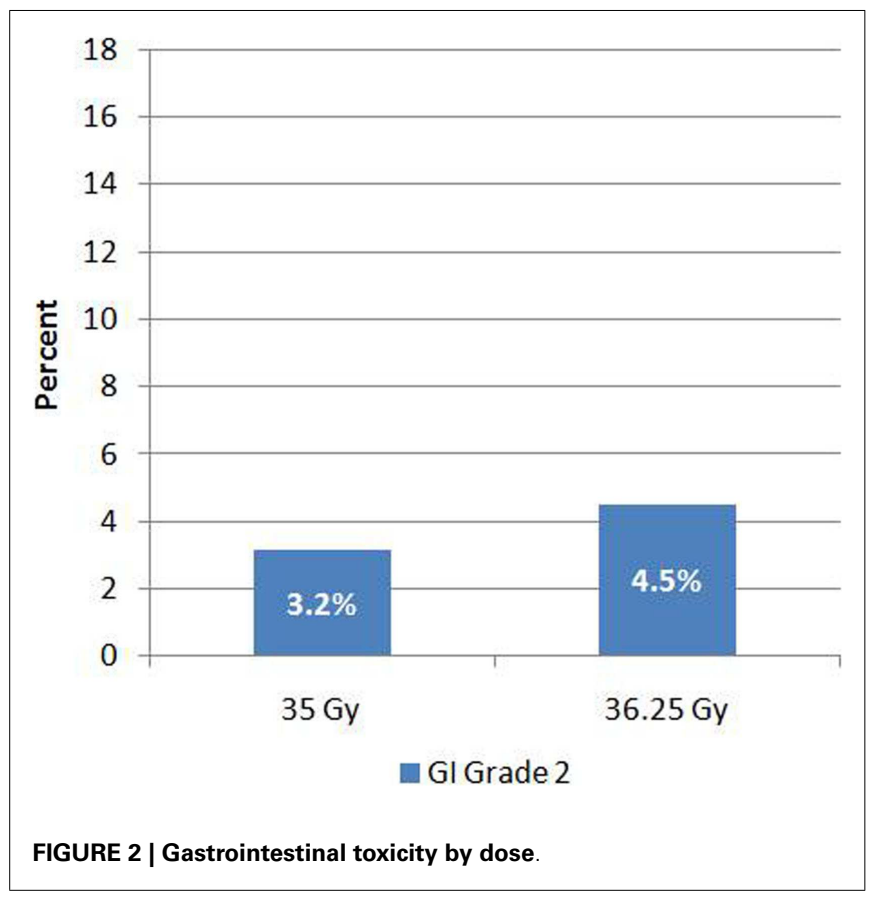

\section{LATE TOXICITY - GASTROINTESTIONAL}

Late Grade 2 bowel toxicity occurred in 21 (4\%) of patients. Of this group, five patients were on anticoagulation therapy with Coumadin. Most common manifestation was rectal bleeding $(85.7 \%)$. Grade 2 toxicity occurred in $3.2 \%(n=5)$ and $4.5 \%$ $(n=16)$ of patients who received 35 and $36.25 \mathrm{~Gy}$, respectively (Figure 2). This difference was not significant $(p=0.48)$. There was no Grade 3-4 bowel toxicity noted. The median time to development of bowel toxicity was 18 months (range, 6-44 months). At last follow-up (median follow-up $=72$ months), 19 of the 21 affected patients experienced resolution of their symptoms.

\section{PROSTATE VOLUME}

Data on prostate volume were available for 336 patients. Median prostate volume was $59.15 \mathrm{cc}(16.8-224 \mathrm{cc})$, and mean prostate volume was $65.3 \mathrm{cc}(\mathrm{SD}=30.2 \mathrm{cc})$. Patients were analyzed based on prostate volume greater than or less than $60 \mathrm{cc}, 173$ patients had prostate volume $\leq 60 \mathrm{cc}$ versus 163 with prostate volume $>60 \mathrm{cc}$. There was higher incidence of both Grade $2(n=19$, $11.6 \%)$ and Grade $3(n=5,3.1 \%)$ toxicity in patients with prostate volume $>60 \mathrm{cc}$, compared to Grade $2(n=12,6.9 \%)$ and Grade $3(n=1,0.6 \%)$ toxicity in patients with prostate volume $\leq 60 \mathrm{cc}$, this trended toward significance $(p=0.051)$. There was no significant difference in GI toxicity between patients with prostate volume $>60 \mathrm{cc}$ (Grade 2 toxicity $n=7,4.3 \%$ ) versus those with prostate volume $\leq 60 \mathrm{cc}$ (Grade 2 toxicity $n=6$, $3.7 \%)$.

\section{QUALITY OF LIFE - EPIC QUESTIONNAIRE}

Prior to treatment, all patients completed the initial EPIC questionnaire to evaluate urinary, bowel, and sexual QOL. At each subsequent time points, patients were requested to fill out the EPIC questionnaire to assess follow-up QOL, but not all patients 


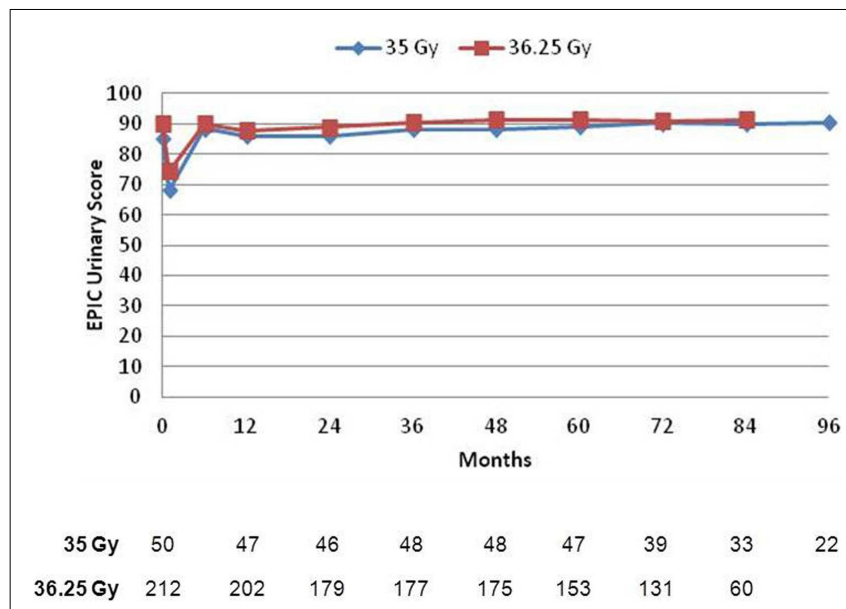

FIGURE 3 | Expanded prostate cancer index composite urinary scores The mean EPIC score is depicted for each time point. A number of patients with completed questionnaires are shown in table below.

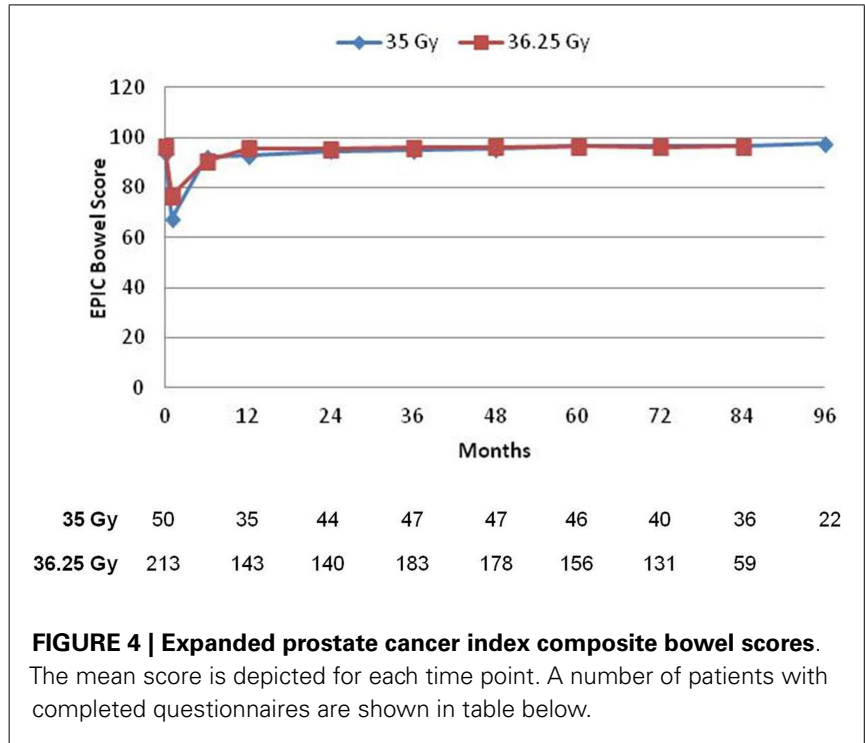

were compliant. Mean scores for all three domains, with the number of patients responding at each follow-up interval, is depicted in Figures 3-5. For urinary (Figure 3) and bowel (Figure 4) domains, mean EPIC scores decreased acutely and then gradually rose back to baseline by one year. After 1 year, mean EPIC scores extending out to 8 years did not differ significantly from baseline. EPIC sexual QOL (Figure 5) declined by 23\% at 6-12 months and remained stable, $67 \%$ of the patients potent at baseline remained potent at last follow-up.

There was no significant difference in EPIC bowel, sexual, or urinary scores between 35 or $36.25 \mathrm{~Gy}$ at any time point.

\section{MULTIVARIATE ANALYSIS}

On univariate analysis, prostate size $>60 \mathrm{cc}$ was found to be a significant $(p=0.03)$ predictor of Grade 2 or higher late GU toxicity (Table 2). Using a higher dose trended toward significance

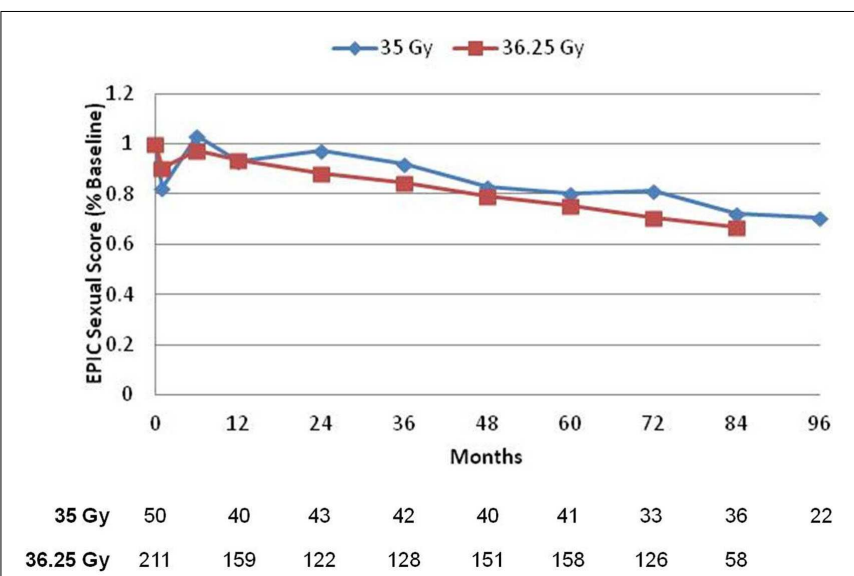

FIGURE 5 | Expanded prostate cancer index composite sexual scores. EPIC sexual scores are reported as a percentage of each respective patient's baseline score. A number of patients with completed questionnaires are shown in table below.

Table 2 | Univariate (UVA) and multivariate (MVA) logistic regression analyses looking at patient characteristics and the effect on Grade 2 or higher late GU toxicity.

\begin{tabular}{|c|c|c|c|}
\hline \multirow{2}{*}{ Factor } & \multirow{2}{*}{$\begin{array}{c}\text { UVA } \\
\qquad p\end{array}$} & \multicolumn{2}{|c|}{ MVA } \\
\hline & & $p$ & RR $(95 \% \mathrm{Cl})$ \\
\hline $\begin{array}{l}\text { Prostate size (above or } \\
\text { below } 60 \mathrm{cc} \text { ) }\end{array}$ & 0.03 & 0.03 & $0.86(0.66-1.13)$ \\
\hline Dose (35 versus $36.25 \mathrm{~Gy}$ ) & 0.051 & $<0.0001$ & $3.31(2.17-5.35)$ \\
\hline $\begin{array}{l}\text { Baseline GU EPIC score } \\
\text { (above or below 90) }\end{array}$ & 0.39 & 0.58 & $0.93(0.71-1.21)$ \\
\hline
\end{tabular}

( $p=0.051)$, whereas baseline GU EPIC score was not significant. Multivariate analysis was performed looking at these three variables. Dose of 36.25 versus $35 \mathrm{~Gy}$ was the only significant variable, with $p<0.0001$ (RR 3.31, 95\% CI 2.17-5.35).

\section{BIOCHEMICAL CONTROL AND PSA}

Actuarial 7-year biochemical recurrence-free survival 95.6, 89.6, and $68.5 \%$ was $95.6 \%$ for low-risk, $89.6 \%$ for intermediate-risk, and $68.5 \%$ for high-risk patients (Figure 6).

For low- and intermediate-risk patients, there was no significant difference in biochemical disease-free survival (bDFS) between 35 versus $36.25 \mathrm{~Gy}(p=0.36)$.

\section{DISCUSSION}

This study has the longest toxicity and QOL follow-up to date for prostate SBRT, and as a result, several important questions can begin to be addressed. The first question is whether SBRT doses of 35-36.25 Gy can be well-tolerated. Prior reports on SBRT, with only several years follow-up, reported excellent QOL outcomes but raised skepticism that late toxicity events would occur after many years. Our results suggest that the incidence of bowel and bladder toxicity continues to remain low, even after extended follow-up. 


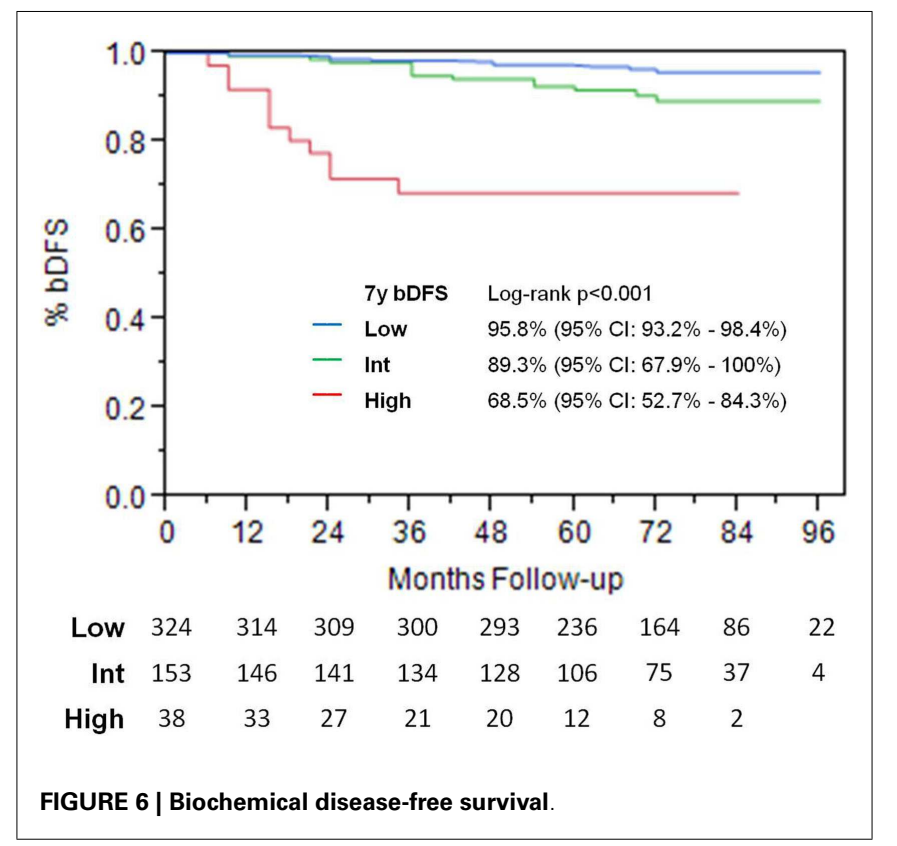

Interestingly, over $90 \%$ of toxicity events occurred within 3 years of treatment, suggesting that the incidence of late toxicity will continue to remain low as more follow-up is obtained. Our low toxicity and excellent QOL are comparable or lower than results published for HDR and LDR brachytherapy, proton beam, and dose-escalated IMRT (14-17).

The low toxicity is consistent with radiobiologic data suggesting that prostate cancer has a very low $\alpha / \beta$ ratio, whereas the normal bowel/bladder tissue has $\alpha / \beta$ ratio of 3 (18), making hypofractionation a logical treatment choice. Assuming $\alpha / \beta$ ratio of 3 (18) for late soft tissue complications, the radiation doses used in this study of 35-36.25 Gy are equivalent to delivering 70-77 Gy at 1.8 Gy per fraction to surrounding normal tissue, this is lower than the dose to normal tissues delivered using standard IMRT. In addition, the ability to utilize tighter margins for SBRT treatment allows for more favorable bladder and rectum DVHs, and translates to mild bowel and bladder toxicity in both the short- and long-term.

In a recent well-publicized article by Yu et al (19), it has been suggested that SBRT may cause more urinary side effects than IMRT. Our data show a toxicity profile and QOL that compares favorably to IMRT. For instance, our overall rate of $9 \%$ Grade 2 urinary toxicity is comparable to Zelefsky's report of 9\% Grade 2 toxicity in 2006 (20). In fact, our rate of 5.7\% late Grade 2 toxicity with $35 \mathrm{~Gy}$, with no Grade 3 events, is arguably better than IMRT (21). Although it is not known, it is likely that patients treated to higher doses were included in the study by Yu. Based on our findings, which suggest 36.25 Gy results in greater toxicity than $35 \mathrm{~Gy}$, we surmise that higher doses will result in even greater rates of toxicity, and likely account for Yu's findings.

Our study also begins to address the question of appropriate SBRT dose. We noted a significant increase in urinary toxicity as the dose rises from 35 to $36.25 \mathrm{~Gy}$. This is equivalent to normal tissue EQD increase from 70 to 77 Gy. Delivering 35 Gy in 5 fractions is equivalent to $200 \mathrm{~Gy}$ BED to the tumor cells, and studies suggest going higher than this dose does not result in better disease control (22). As a result, we hypothesize that $35 \mathrm{~Gy}$ may be the optimal dose for low- and intermediate-risk prostate cancer, and higher doses may result in increased toxicity without increased biochemical control. Recently, published studies on prostate SBRT, documenting unacceptably high rates of toxicity with higher radiation doses, are consistent with this hypothesis (23), and merits further study. Of note, the current RTOG 0938 trial is treating patients to dose of 36.25 in 5 fractions, and our data suggest that there may be greater toxicity with this higher dose.

Despite the higher toxicity noted in patients treated to $36.25 \mathrm{~Gy}$, the QOL data did not reflect any disparity between the two groups by dose. Most bowel and bladder toxicity resolved with time and symptomatic treatment; as a result, QOL was not impacted for significant lengths of time and in most cases had returned to patient baseline once toxicity resolved. We believe this likely explains why QOL data between the two doses remained similar, whereas RTOG toxicity was significantly higher in the $36.25 \mathrm{~Gy}$ patient cohorts though the incidence of toxicity was greater with the higher dose.

The potential impact of prostate size and pre-treatment urinary function on long-term urinary toxicity has been an interesting question for study. To address this, a multivariate analysis was performed, and neither gland size nor impaired baseline urinary QOL predicted for late GU toxicity. These results are reassuring and suggest large prostate size and baseline poor urinary function should not automatically preclude patients from being considered for SBRT.

Regardless of dose, rectal toxicity remained quite mild. We do not believe the low rate of rectal toxicity can be attributed to the use of amifostine. Other groups have published reports on their prostate SBRT experience, and have also found low toxicity without the use of Amifostine $(1,3,8)$. In fact, in our clinic, use of Amifostine was discontinued since early 2010, and thus far, we have not observed any increases in rectal toxicity.

Finally, we report encouraging potency preservation rates, with $67 \%$ of initially potent at baseline able to retain good function. This is similar to outcomes for HDR brachytherapy (16) and more favorable than outcomes reported for dose-escalated IMRT (15). In fact, potency preservation rates after SBRT are only slightly worse than what one would expect in a similar cohort of men in this age group, who did not receive any radiotherapy (24). The decrease in potency is reflected in the overall reduction of sexual QOL scores. Since no significant difference in sexual QOL was observed between the doses used, we postulate this is due to the tight constraints to the penile bulb that were utilized for both doses, and conjecture that penile bulb dose may be an important predictor of potency preservation.

It should be noted that we delivered all treatments daily (QD), Monday through Friday. King suggested in his 2009 article that every other day (QOD) treatments to $36.25 \mathrm{~Gy}$ yields less rectal toxicity, compared to QD (10). He reported 18\% Grade 2 rectal toxicity in patients treated QD, significantly higher than our findings, which suggests that there may have been a dosimetric issue with these early patients. In a more recent 2012 update (1), he found a lower rate of Grade 1 rectal and urinary toxicity with QOD compared to QD, but no significant difference in Grade 2-3. In addition, his total number of patients is fairly low at 67 , making 
it difficult to draw any definitive conclusions. Therefore, contrary to popular belief, we feel it is not established that QOD treatments yield less rectal or urinary toxicity. Particularly with treatment delivered daily to $35 \mathrm{~Gy}$, we shown very low rates of Grade 2-3 toxicity, with high efficacy. Our data, with many more patients, suggest that dose, rather than the schedule, is the most important predictor of late rectal toxicity.

Prostate SBRT has the added advantages of patient convenience and decreased healthcare cost. Only 5 treatment visits are required, in contrast to 40-45 for conventionally fractionated radiation. Furthermore, the current Medicare rate is substantially lower for prostate SBRT, which costs $\$ 21,000$ in contrast to $\$ 32,000$ for IMRT and $\$ 53,000$ for protons.

\section{CONCLUSION}

Cyberknife SBRT produces excellent long-term biochemical control rates with acceptably low rates of long-term toxicity, similar to other radiotherapy modalities. Our results suggest that $35 \mathrm{~Gy}$ is as effective as 36.25 Gy for low- and low-intermediate-risk patients, and has significantly less late Grade 2-3 urinary toxicity. Further follow-up extending beyond 10 years will be obtained to determine the durability of response and incidence of late toxicity. Both prospective and randomized studies are indicated to confirm these encouraging results.

\section{REFERENCES}

1. King CR, Brooks JD, Gill H, Presti JC Jr. Long-term outcomes from a prospective trial of stereotactic body radiotherapy for low-risk prostate cancer. Int J Radiat Oncol Biol Phys (2012) 82:877-82. doi:10.1016/j.ijrobp.2010.11.054

2. Katz AJ, Santoro M, Diblasio F, Ashley R. Stereotactic body radiotherapy for localized prostate cancer: disease control and quality of life at 6 years. Radiat Oncol (2013) 8:118. doi:10.1186/1748-717X-8-118

3. Freeman DE, King CR. Stereotactic body radiotherapy for low-risk prostate cancer: five-year outcomes. Radiat Oncol (2011) 6:3. doi:10.1186/1748-717X-6-3

4. Chen LN, Suy S, Uhm S, Oermann EK, Ju AW, Chen V, et al. Stereotactic body radiation therapy (SBRT) for clinically localized prostate cancer: the Georgetown University experience. Radiat Oncol (2013) 8:58. doi:10.1186/1748717X-8-58

5. McBride SM, Wong DS, Dombrowski JJ, Harkins B, Tapella P, Hanscom HN, et al. Hypofractionated stereotactic body radiotherapy in low-risk prostate adenocarcinoma: preliminary results of a multi-institutional phase 1 feasibility trial. Cancer (2012) 118:3681-90. doi:10.1002/cncr.26699

6. King CR, Freeman D, Kaplan I, Fuller D, Bolzicco G, Collins S, et al. Stereotactic body radiotherapy for localized prostate cancer: pooled analysis from a multiinstitutional consortium of prospective phase II trials. Radiother Oncol (2013) 109:217-21. doi:10.1016/j.radonc.2013.08.030

7. King CR, Collins S, Fuller D, Wang PC, Kupelian P, Steinberg M, et al. Healthrelated quality of life after stereotactic body radiation therapy for localized prostate cancer: results from a multi-institutional consortium of prospective trials. Int J Radiat Oncol Biol Phys (2013) 87:939-45. doi:10.1016/j.ijrobp.2013. 08.019

8. Romanelli P, Schaal DW, Adler JR. Image-guided radiosurgical ablation of intraand extra-cranial lesions. Technol Cancer Res Treat (2006) 5:421-8.

9. Simone NL, Ménard C, Soule BP, Albert PS, Guion P, Smith S, et al. Intrarectal amifostine during external beam radiation therapy for prostate cancer produces significant improvements in quality of life measured by EPIC score. Int J Radiat Oncol Biol Phys (2008) 70:90-5. doi:10.1016/j.ijrobp.2007.05.057

10. King CR, Brooks JD, Gill H, Pawlicki T, Cotrutz C, Presti JC Jr. Stereotactic body radiotherapy for localized prostate cancer: interim results of a prospective phase II clinical trial. Int J Radiat Oncol Biol Phys (2009) 73:1043-8. doi:10.1016/j.ijrobp.2008.05.059

11. Roach M III, Hanks G, Thames H Jr, Schellhammer P, Shipley WU, Sokol $\mathrm{GH}$, et al. Defining biochemical failure following radiotherapy with or without hormonal therapy in men with clinically localized prostate cancer: recommendations of the RTOG-ASTRO Phoenix Consensus Conference. Int J Radiat Oncol Biol Phys (2006) 65:965-74. doi:10.1016/j.ijrobp.2006.04.029

12. Wei JT, Dunn RL, Litwin MS, Sandler HM, Sanda MG. Development and validation of the expanded prostate cancer index composite (EPIC) for comprehensive assessment of health-related quality of life in men with prostate cancer. Urology (2000) 56:899-905. doi:10.1016/S0090-4295(00)00858-X

13. Cox JD, Stetz J, Pajak TF. Toxicity criteria of the radiation therapy oncology group (RTOG) and the European organization for research and treatment of cancer (EORTC). Int J Radiat Oncol Biol Phys (1995) 31:1341-6. doi:10.1016/0360-3016(95)00060-C

14. Hoppe BS, Nichols RC, Henderson RH, Morris CG, Williams CR, Costa J, et al. Erectile function, incontinence, and other quality of life outcomes following proton therapy for prostate cancer in men 60 years old and younger. Cancer (2012) 118:4619-26. doi:10.1002/cncr.27398

15. Coen JJ, Paly JJ, Niemierko A, Weyman E, Rodrigues A, Shipley WU, et al. Long-term quality of life outcome after proton beam monotherapy for localized prostate cancer. Int J Radiat Oncol Biol Phys (2012) 82:e201-9. doi:10.1016/j. ijrobp.2011.03.048

16. Demanes DJ, Rodriguez RR, Schour L, Brandt D, Altieri G. High-doserate intensity-modulated brachytherapy with external beam radiotherapy for prostate cancer: California endocurietherapy's 10-year results. Int J Radiat Oncol Biol Phys (2005) 61:1306-16. doi:10.1016/j.ijrobp.2004.08.014

17. Frank SJ, Pisters LL, Davis J, Lee AK, Bassett R, Kuban DA. An assessment of quality of life following radical prostatectomy, high dose external beam radiation therapy and brachytherapy iodine implantation as monotherapies for localized prostate cancer. J Urol (2007) 177:2151-6. doi:10.1016/j.juro.2007.01.134

18. Marzi S, Saracino B, Petrongari MG, Arcangeli S, Gomellini S, Arcangeli G, et al. Modeling of alpha/beta for late rectal toxicity from a randomized phase II study: conventional versus hypofractionated scheme for localized prostate cancer. J Exp Clin Cancer Res (2009) 28:117. doi:10.1186/1756-9966-28-117

19. Yu JB, Cramer LD, Herrin J, Soulos PR, Potosky AL, Gross CP. Stereotactic body radiation therapy versus intensity-modulated radiation therapy for prostate cancer: comparison of toxicity. J Clin Oncol (2014) 32:1195-201. doi:10.1200/JCO.2013.53.8652

20. Zelefsky MJ, Chan H, Hunt M, Yamada Y, Shippy AM, Amols H. Long-term outcome of high dose intensity modulated radiation therapy for patients with clinically localized prostate cancer. J Urol (2006) 176:1415-9. doi:10.1016/j.juro. 2006.06.002

21. Alicikus ZA, Yamada Y, Zhang Z, Pei X, Hunt M, Kollmeier M, et al. Ten-year outcomes of high-dose, intensity-modulated radiotherapy for localized prostate cancer. Cancer (2011) 117:1429-37. doi:10.1002/cncr.25467

22. Zaorsky NG, Hurwitz M. Evaluation of biologically equivalent dose escalation, clinical outcome, and toxicity in prostate cancer radiation therapy: a meta-analysis of 12,000 patients. Int J Radiat Oncol Biol Phys (2013) 87:S24. doi:10.1016/j.ijrobp.2013.06.067

23. Kim DW, Cho LC, Straka C, Christie A, Lotan Y, Pistenmaa D, et al. Predictors of rectal tolerance observed in a dose-escalated phase 1-2 trial of stereotactic body radiation therapy for prostate cancer. Int J Radiat Oncol Biol Phys (2014) 89:509-17. doi:10.1016/j.ijrobp.2014.03.012

24. Selvin E, Burnett AL, Platz EA. Prevalence and risk factors for erectile dysfunction in the US. Am J Med (2007) 120:151-7. doi:10.1016/j.amjmed.2006.06.010

Conflict of Interest Statement: The authors declare that the research was conducted in the absence of any commercial or financial relationships that could be construed as a potential conflict of interest.

Received: 20 August 2014; paper pending published: 14 September 2014; accepted: 14 October 2014; published online: 28 October 2014.

Citation: Katz AJ and Kang J (2014) Quality of life and toxicity after SBRT for organ-confined prostate cancer, a 7-year study. Front. Oncol. 4:301. doi: 10.3389/fonc.2014.00301

This article was submitted to Radiation Oncology, a section of the journal Frontiers in Oncology.

Copyright $\odot 2014 \mathrm{Katz}$ and Kang. This is an open-access article distributed under the terms of the Creative Commons Attribution License (CC BY). The use, distribution or reproduction in other forums is permitted, provided the original author(s) or licensor are credited and that the original publication in this journal is cited, in accordance with accepted academic practice. No use, distribution or reproduction is permitted which does not comply with these terms. 